\title{
Reply to comment by Huntley on "Isochron dating of sediments using luminescence of K-feldspar grains"
}

\author{
Bo $\mathrm{Li}^{1}{ }^{1}$ Sheng-Hua $\mathrm{Li}^{1}{ }^{1}$ and Hui Zhao ${ }^{2}$ \\ Received 17 November 2010; revised 13 January 2011; accepted 19 January 2011; published 2 March 2011.
}

Citation: Li, B., S.-H. Li, and H. Zhao (2011), Reply to comment by Huntley on "Isochron dating of sediments using luminescence of K-feldspar grains,” J. Geophys. Res., 116, F01013, doi:10.1029/2010JF001931.

\section{Introduction}

[1] In our isochron studies using grains of different sizes, we observed that the IRSL ages obtained from K-feldspar without correction for fading show an increase with increasing grain size [Li et al., 2007, 2008]. Huntley [2011a] argued that this result was caused by different fading rates for grains of different sizes or by different source materials for different sizes of grains. We replied to his comment [Li et al., 2011], suggesting that the phenomenon could be explained by there being different fading rates for the IRSL signals produced by natural and laboratory irradiation [Li et al., 2007, 2008]. Instead of applying a correction to the whole of the IRSL signal [Zhao and $\mathrm{Li}, 2002$ ], Li et al. [2008] deduced that the IRSL signal derived from the internal dose rate does not fade. An isochron dating method using the internal dose was proposed, and it appeared to be able to give reliable ages for well-bleached aeolian samples [Li et al., 2008]. We are pleased that Huntley [2011b] has put forward new comments and some valuable explanations for our isochron data [Li et al., 2008] and that we can take the opportunity to reply to his comments.

\section{Difference Between Internal Dose and External Dose in Fading of IRSL Signal}

[2] The deduction that the IRSL signals due to the internal dose and external dose have different fading rates is based on empirical results which showed that the ages calculated using the internal dose is higher than those calculated from the external dose using the isochron method [Li et al., 2007, 2008]. As mentioned by Huntley [2011b], one method of verifying this deduction is to plot the ratio of the uncorrected $\mathrm{K}$-feldspar age to the true age as a function of the external dose rate and see whether an extrapolation of the data set yields unity at zero external dose rate. Li et al. [2008, Figure 10] showed such a plot and indeed seemed not to support this assertion. However, the underestimation factor (the ratio of the uncorrected $\mathrm{K}$-feldspar age to the true age) will depend not only on the actual anomalous fading rate in nature but also on the sample's age. Indeed, it has been shown elsewhere that older

\footnotetext{
${ }^{1}$ Department of Earth Sciences, University of Hong Kong, Hong Kong. ${ }^{2}$ Key Laboratory of Desert and Desertification, Cold and Arid Regions Environment and Engineering Research Institute, Chinese Academy of Science, Lanzhou, China.

Copyright 2011 by the American Geophysical Union. 0148-0227/11/2010JF001931
}

samples tend to have larger age underestimation [ $\mathrm{Li}$ and $\mathrm{Li}$, 2008; Kars et al., 2008]. Hence, it is not appropriate to extrapolate all the data sets in Figure 10 [ $\mathrm{Li}$ et al., 2008] without consideration of the ages and source regions of the $\mathrm{K}$-feldspar grains, since the latter may result in different anomalous fading properties. Only when samples have the same fading properties and have similar ages could one expect extrapolation of the ratios to result in unity for zero external dose rate.

[3] Taking account of both the ages and geological settings of the samples in Figure 10 [Li et al., 2008], we have divided the data sets into three groups of similar age range and similar geological proximity or fading properties: the first group includes samples HLD3, SY3, and WG3; the second group includes samples Sm0404 and Sm5; and the third group is made up of the remaining samples. If we consider the different groups individually, three lines can be drawn from unity at zero external dose rate and passing through the three groups (Figure 1). Figure 1 cannot disprove the possibility that different contributions of the external dose and internal dose can result in the different underestimation in IRSL ages, that is, the higher contribution from the external dose, the more underestimation in their ages.

\section{Anomalous Fading in the Laboratory and in Nature}

[4] Several samples (D4, Dgw5, Sm1, Sm2, Sm3, and Sm4) have uncorrected K-feldspar IRSL ages in agreement with the independent ages (in this case quartz OSL ages) within uncertainties, although they are expected to have lower IRSL ages based on the anomalous fading observed in laboratory fading tests. Huntley [2011b] raises doubts concerning the validity of our equivalent dose estimation procedure; however, the procedure used for equivalent dose estimation should be reliable as a good dose recovery test was obtained [Li et al., 2007]. Furthermore, for other samples shown in Figure 1 which have uncorrected K-feldspar ages lower than independent ages, the isochron ages are also in agreement with the independent ages. This suggests that the slopes of the lines $F$ are not simply proportional to the equivalent doses and also not dependent on the extent of underestimation or anomalous fading.

[5] Huntley [2011b] points out that the fading-corrected ages are in agreement with the independent ages for some of our samples (e.g., WG3, HLD3, and SY3) but not for others. This could be explained by the laboratory-measured fading rates not necessarily reflecting the rate of anomalous fading 


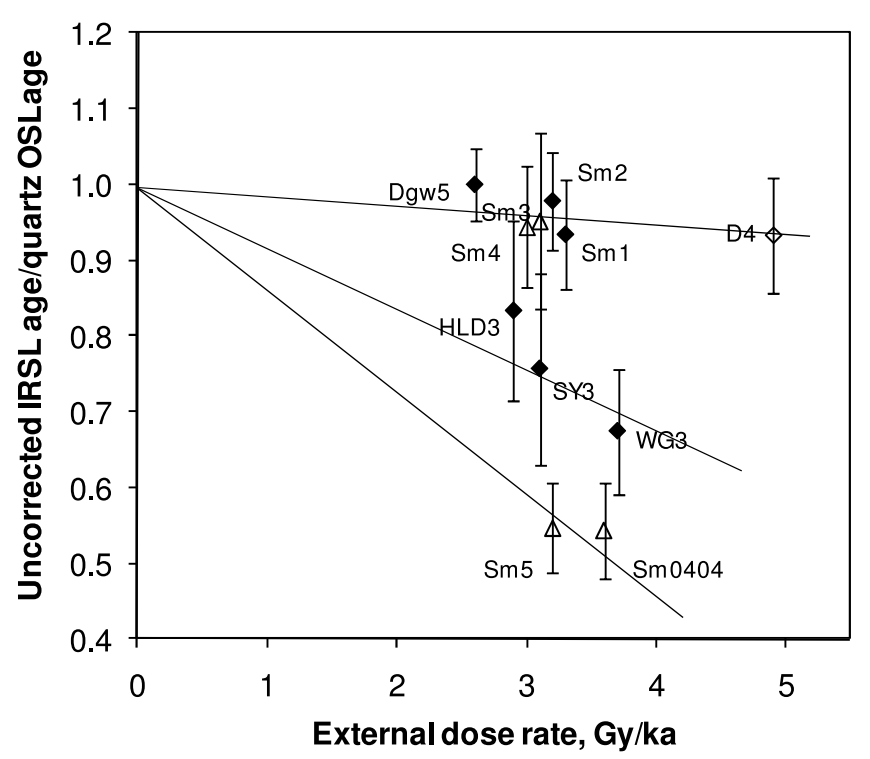

Figure 1. The ratios of uncorrected IRSL age to quartz OSL age for 125-150 mm diameter grains, plotted against the external dose rates (redrawn from Li et al. [2008, Figure 10]).

in nature. In particular, the anomalous fading rates measured in the laboratory may be dependent on the natural dose received and the dose rate during the burial period [ $\mathrm{Li}$ and Li, 2008; Kars et al., 2008]. Several studies have shown that anomalous fading corrections made using the laboratory measured fading rate failed [e.g., Wallinga et al., 2007; Kars et al., 2010; Reimann et al., 2010]. These studies showed that the fading-corrected ages might overestimate or underestimate the true ages, indicating that some natural processes cause a change in the fading rate in nature; thus, the laboratory fading test may not reflect the real fading rate that takes place in the natural process. The consistency between fading-corrected ages and true ages could result from a balance between the processes for some samples, but not for all; hence, the application of a fading correction using the laboratory measured fading rate [Huntley and Lamothe, 2001] must be viewed with caution.

\section{Explanations for the Isochron Dating Results}

[6] Our deduction that the part of the IRSL signal derived from the internal dose does not fade is based on experimental results [Li et al., 2007, 2008]. We agree with Huntley [2011a, 2011b] that there is no clear physical mechanism for such a phenomenon; however, the aim of our study was to develop a technique which could both overcome any environmental dose rate changes and avoid having to make a correction for anomalous fading. We agree with Huntley [2011b] that our inference of a nonfading IRSL signal from the internal dose might not be true; it is only a possible explanation for this phenomenon. Here we present some other possible explanations which do not contradict conventional radiation physics, and we will be glad to receive additional explanations from others.

[7] In the original paper [Li et al., 2007] we suggested that the decay of radioactive isotopes internal to $\mathrm{K}$-feldspar grains (i.e., ${ }^{40} \mathrm{~K}$ and ${ }^{87} \mathrm{Rb}$ ) into new isotopes (i.e., ${ }^{40} \mathrm{Ca}$ and
${ }^{87} \mathrm{Sr}$ ) during the natural decay process may be the cause of different fading rates between the IRSL signal created by the radiation emanating from inside the $\mathrm{K}$-feldspar crystal and that from outside. The radioactive decay might have created new defects and caused changes in the crystal microstructure, which might either create stable (or nonfading) traps or prevent the tunneling process for the trapped electrons related to these defects. Following this line of reasoning, since the internal dose also relates to the decay of ${ }^{40} \mathrm{~K}$ and ${ }^{87} \mathrm{Rb}$, the portion of the equivalent dose corresponding to the newly created stable traps would be proportional to the internal dose. However, a problem with this possible explanation is that the concentration of stable traps created should be independent of grain size.

[8] Another possible explanation relates to the filling of electron traps. The larger K-feldspar grains have a higher dose rate (internal plus external dose rates) than the smaller grains. If this higher dose rate could have resulted in a higher electron filling probability, a lower fading rate in nature would be inferred for the larger grains compared with the smaller grain. As a result, age underestimation due to anomalous fading for larger grains is less than for smaller grains, and the slope of the trend line $F$ in the isochron plot will increase accordingly; this would result in all grain sizes having different degrees of underestimation. The apparent effect is that the increased slope of $F$ would give an age close to the true age. Such an effect should be dependent on the fading rate of the samples, that is, less dependence for samples with smaller amounts of fading, which agrees with our results that the isochron method gave ages consistent with expected ages when applied to samples with different extents of underestimation in apparent K-feldspar IRSL ages [Li et al., 2008, Figures 5 and 6]. However, this result is in contrast to the results in Figure 10 [Li et al., 2008], which show that a sample with a higher dose rate tends to have larger age underestimation.

[9] Another possible cause of the effect that we observe is related to internal alpha particle emission. It has been shown that there is a contribution of alpha dose from internal $\mathrm{U}$ and Th contents in K-feldspar grains [Zhao and Li, 2005]. Because of the short penetration distance $(\sim 25 \mu \mathrm{m})$ of alpha particles in feldspar [Aitken, 1985], fewer alpha particles will escape from feldspar grains with diameters larger than this distance. The larger the grain size, the fewer alpha particles will escape. As the high-energy alpha particle is finally stopped in the crystal, defects may be formed that relate to the electron traps. Thus, more defects are formed in larger grains. It is possible that these newly formed defects are associated with the creation of stable traps, and this would result in relatively less fading in larger grains during natural irradiation than in smaller grains. As a result, the natural fading rate would be dependent on the grain size, and the IRSL age would depend on grain size for K-feldspar [Li et al., 2007]. However, because the internal dose rate is also proportional to grain size, it appears that the natural fading rate, and hence the apparent age, is dependent on the internal dose rate. The preheat up to $300^{\circ} \mathrm{C}$ used in laboratory measurements could result in diffusion of these defects, and this might cause such a grain size dependence to disappear in laboratory fading measurements. Such a diffusion process is required since similar laboratory fading rates for different grain sizes were observed [Li et al., 2007]. 
[10] We acknowledge that a satisfactory physical mechanism for explanation of the behavior of $\mathrm{K}$-feldspar presented in our experimental results is needed. The explanations given above are not contrary to conventional physics but are entirely speculative. Indeed, several complicated processes could have contributed to the apparent result that the internal dose gives ages consistent with the true ages. However, the aim of the isochron method is to provide an alternative approach for dating sediments with changes in past environmental dose rate, and it is able to avoid the anomalous fading problem.

\section{Conclusion}

[11] The isochron dating method can give reliable ages, though a viable physical mechanism for the behavior behind it is still to be found.

\section{References}

Aitken, M. J. (1985), Thermoluminescence Dating, Academic, London.

Huntley, D. J. (2011a), Comment on "Isochron measurements of naturally irradiated K-feldspar grains" by B. Li, S.-H. Li, A. G. Wintle and H. Zhao. Radiation Measurements 42, 1315-1327, 2007, Radiat. Meas., 46, 166-167, doi:10.1016/j.radmeas.2010.08.018.

Huntley, D. J. (2011b), Comment on "Isochron dating of sediments using luminescence of K-feldspar grains" by B. Li et al., J. Geophys. Res., doi:10.1029/2010JF001856, in press.

Huntley, D. J., and M. Lamothe (2001), Ubiquity of anomalous fading in $\mathrm{K}$-feldspars and the measurement and correction for it in optical dating, Can. J. Earth Sci., 38, 1093-1106, doi:10.1139/cjes-38-7-1093.

Kars, R. H., J. Wallinga, and K. M. Cohen (2008), A new approach towards anomalous fading correction for feldspar IRSL dating - tests on samples in field saturation, Radiat. Meas., 43, 786-790, doi:10.1016/j.radmeas. 2008.01.021.
Kars, R. H., J. Wallinga, and F. S. Busschers (2010), Critical view on $\mathrm{K}$-feldspar post-IR IR dating, paper presented at UK Luminescence and Electron Spin Resonance Dating Conference, Sch. of Geogr. and the Environ., Univ. of Oxford, Oxford, U. K., 8-10 Sep.

$\mathrm{Li}, \mathrm{B}$. , and S.-H. Li (2008), Investigations of the dose-dependent anomalous fading rate of feldspar from sediments, J. Phys. D Appl. Phys., 41, 225502, doi:10.1088/0022-3727/41/22/225502.

Li, B., S. H. Li, A. G. Wintle, and H. Zhao (2007), Isochron measurements of naturally irradiated K-feldspar grains, Radiat. Meas., 42, 1315-1327, doi:10.1016/j.radmeas.2007.09.008.

Li, B., S.-H. Li, A. G. Wintle, and H. Zhao (2008), Isochron dating of sediments using luminescence of K-feldspar grains, J. Geophys. Res., 113, F02026, doi:10.1029/2007JF000900.

Li, B., S.-H. Li, A. G. Wintle, and H. Zhao (2011), Anomalous fading: A reply to the comment by Huntley on "Isochron measurements of naturally irradiated K-feldspar grains," Radiat. Meas., 46, 164-165, doi:10.1016/j.radmeas.2010.08.020.

Reimann, T., S. Tsukamoto, M. Naumann, and M. Frechen (2010), The potential of using feldspars for optical dating of young coastal sediments-A test case from Darss-Zingst peninsula (southern Baltic Sea coast), Quat. Geochronol., doi:10.1016/j.quageo.2010.10.001, in press.

Wallinga, J., A. J. J. Bos, P. Dorenbos, A. S. Murray, and J. Schokker (2007), A test case for anomalous fading correction in IRSL dating, Quaternary Geochronol., 2, 216-221, doi:10.1016/j.quageo.2006. 05.014 .

Zhao, H., and S.-H. Li (2002), Luminescence isochron dating: A new approach using different grain sizes, Radiat. Prot. Dosimetry, 101, 333-338.

Zhao, H., and S.-H. Li (2005), Internal dose rate to K-feldspar grains from radioactive elements other than potassium, Radiat. Meas., 40, 84-93, doi:10.1016/j.radmeas.2004.11.004.

B. Li and S.-H. Li, Department of Earth Sciences, University of Hong Kong, James Lee Science Bldg., Pokfulam Road, Hong Kong 999077. (shli@hku.hk)

H. Zhao, Key Laboratory of Desert and Desertification, Cold and Arid Regions Environment and Engineering Research Institute, Chinese Academy of Science, 320 Donggang West Rd., Lanzhou 730000, China. 